\title{
Urethral dysfunction due to alloxan-induced diabetes. Urodynamic evaluation and action of sildenafil citrate ${ }^{1}$
}

\author{
Ana Beatriz Gomes de Souza Pegorare', Marco Antonio Gonçalves ${ }^{\text {II }}$, Alessandra Martiniano de Oliveira ${ }^{\text {III }}$, Antonio Antunes \\ Rodrigues Junior ${ }^{\mathrm{IV}}$, Silvio Tucci Jrv ${ }^{\mathrm{V}}$, Haylton Jorge Suaid ${ }^{\mathrm{VI}}$ \\ DOI: http://dx.doi.org/10.1590/S0102-86502014000400009 \\ ${ }^{\mathrm{I}}$ Fellow PhD degree, Postgraduate Program in Surgery, Department of Surgery and Anatomy, School of Medicine of Ribeirao Preto, University of Sao \\ Paulo (FMRP-USP), Ribeirao Preto-SP, Brazil. Surgical procedures, acquisition and analysis of data, manuscript writing.

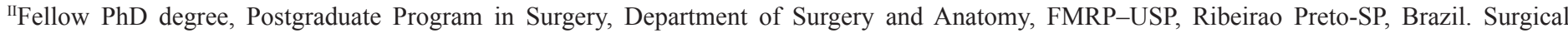 \\ procedures, analysis of data, manuscript writing.

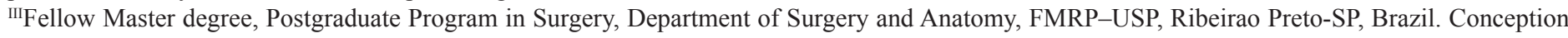 \\ and design of the study, interpretation of data.

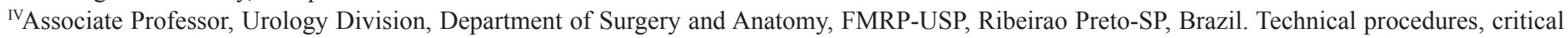 \\ revision. \\ vAssociate Professor, Urology Division, Department of Surgery and Anatomy, FMRP, Ribeirao Preto-SP, Brazil. Critical revision. \\ ${ }^{\mathrm{V}}$ Associate Professor, Division of Urology, Department of Surgery and Anatomy, FMRP-USP, Ribeirao Preto-SP, Brazil. Design the protocol, final \\ approval of the version to be published.
}

\section{ABSTRACT}

PURPOSE: To evaluate the effect of diabetes mellitus and of sildenafil citrate on female urethral function.

METHODS: Twenty nine female rats were divided into four groups: $G 1$ - $(n=9)$, normal rats; $G 2$ - $(n=6)$, normal rats treated with sildenafil citrate; $\mathrm{G} 3$ - $(\mathrm{n}=9)$ rats with alloxan-induced diabetes; $\mathrm{G} 4$ - $(\mathrm{n}=5)$ rats with alloxan-induced diabetes treated with sildenafil citrate. Under anesthesia, urodynamic evaluation was performed by cystometry and urethral pressure simultaneously.

RESULTS: A significant increase in urethral pressure was observed during micturition.

CONCLUSION: Sildenafil citrate can partially reduced urethral pressure in diabetic female rats.

Key words: Diabetes Mellitus. Urethra. Urinary Bladder. Rats. 


\section{Introduction}

Diabetes mellitus (DM) is a metabolic dysfunction characterized by a defect in the action and/or secretion of insulin resulting in hyperglycemia. The estimate is that there are more than 150 million in the world ${ }^{1}$.

Diabetic cystopathy (DC) is one of the most common complications of DM involving high costs for the health system. Dysfunctions of the urinary tract have been identified in more than $50 \%$ of diabetic patients even when they are asymptomatic ${ }^{2}$.

The classical symptoms of DC are reduced bladder sensitivity, reduced detrusor contractility and incomplete bladder emptying resulting in post-voiding residue ${ }^{3,4}$. In addition to these complications, DM also induces changes in bladder mass and in the composition of the parenchyma and compliance of the organ ${ }^{2}$. However, the classical symptoms are not always observed in all diabetic patients, with a wide variety of symptoms commonly occurring. There was also demonstrated increased urinary frequency associated with bladder hyperactivity in the initial phase of the disease ${ }^{5}$.

Nitric oxide (NO) acts as a non-adrenergic and noncholinergic neurotransmitter in the bladder and the urethra and promotes the relaxation of smooth muscle fibers by the activation of guanylate cyclase, which is responsible for the transformation of GMP to GMPc. Since sildenafil citrate inhibits the activity of phsphodiesterase-5, which promotes GMPc hydrolysis, there is an increase in this compound. Thus, there is a scientific basis for the use of sildenafil not only for the treatment of erectile dysfunction, but also for detrusor hyperactivity ${ }^{6}$.

The objective of the present study was to assess the effects of sildenafil citrate on the function of the lower urinary tract after six weeks of DM induction.

\section{Methods}

All procedures involving animals were in accordance with the guidelines established by COBEA (Brazilian College on Animal Experimentation) and approved by the Ethics Committee on Animal Experimentation of School of Medicine of Ribeirao Preto (CETEA) number 035/2009.

Twenty-nine female Wistar rats (Rattus norvegicus albinus) of the same age weighing on average $250 \mathrm{~g}$ were used. The animals were house in collective cages at room temperature on sunlight cycle, with water and ration ad libitum. Diabetes mellitus (DM) was induced at random in 14 rats by a single intraperitoneal injection of alloxan, $40 \mathrm{mg} / \mathrm{kg}$ body weight, dissolved in $0.05 \mathrm{M}$ sodium citrate, $\mathrm{pH} 4.5$, at $4^{\circ} \mathrm{C}$. Blood glucose level was determined by the glucose oxidation method (Accu-Check Complete System, Roche) 72 hours after alloxan administration. All diabetic animals had a glycemia level of more than $300 \mathrm{mg} / \mathrm{dl}$.

Six weeks after the induction of DM, the animals were divided at random into two groups, i.e., animals studied six weeks after the induction of diabetes (group 3,n=9) and five animals studied six weeks after the induction of diabetes and treated with sildenafil citrate injected intraperitoneally at the dose of $1 \mathrm{mg} / \mathrm{kg}$ weight. Urodynamic evaluation was performed 1 hour after the administration of this medication.

The remaining healthy animals were divided into two groups: group $1(n=9)$ no treatment, and group $2(n=6)$ healthy animals treated with sildenafil citrate.

All animals were kept under ideal conditions on a 12 hour light cycle with free access to water and ration.

\section{Urodynamic evaluation}

The evaluation was performed after intraperitoneal anesthesia with urethane $(1.25 \mathrm{mg} / \mathrm{kg} \text { weight })^{6}$. After suprapubic median laparotomy, a PF-50 polyethylene catheter was introduced and fixed on the bladder fundus and exteriorized by counter- opening in the dorsolateral region. The absence of local extravasation and catheter permeability were checked ${ }^{7}$ and cystometry was performed through this catheter.

The parameters analyzed in the cystometry evaluation were: maximum micturition pressure (MMP), bladder contraction frequency $(\mathrm{F})$, bladder contraction intensity $(\mathrm{CI})$, time of bladder filling (TF), and time of bladder contraction (TC). Bladder capacity (C) was obtained by multiplying TF by flow.

For the determination of urethral pressure (UP) a polyethylene catheter $(0.64 \mathrm{~mm}$ outer diameter and $0.50 \mathrm{~mm}$ inner diameter) was positioned at the level of the bladder neck and connected in "Y" to the system for pressure recording. Saline solution was infused through the catheter with an infusion pump at a flow of $0.75 \mathrm{ml} / \mathrm{minute}$.

The cystometric and urethral pressure recordings were obtained with a Dynamed $^{\circledR}$ instrument, model Dynapack MPX816 , with a Y connection to the cystostomy and urethral catheters and to the continuous infusion pump regulated at a flow of 0.75 $\mathrm{mL} / \mathrm{min}$, which permitted a simultaneous continuous recording of vesical and urethral pressure. The transducer for the recording of urethral pressure was positioned at the level of the pubic symphysis. Data were collected for 10 minutes and analyzed with the UroMaster II software. 
Each animal was submitted to urodynamic evaluation for 30 minutes and sacrificed while still under the effect of anesthesia.

Data were analyzed based on the following parameters: mean urethral pressure during detrusor contraction (UPC) and mean urethral pressure during bladder filling (UPF).

\section{Statistical analysis}

The obtained values of parameters of cystometry and urethral pressure recordings were evaluated using nonparametric Kruskal Wallis with Dunn post-test, considering significant differences with a $\mathrm{p}<0.05$. The results were expressed as mean \pm standard deviation (SD). Calculations were made using GraphPad Prism 3.02.

\section{Results}

The mean serum glucose level of female rats with alloxan-induced diabetes was $400.0 \mathrm{mg} / \mathrm{dl}$, as opposed to mean pre-induction levels of $100 \mathrm{mg} / \mathrm{dl}$.

\section{Functional evaluation}

No significant difference was observed between groups in the analysis of MMP $(p=0.633), B C(p=0.1003), F(p=.5717)$ or TF $(\mathrm{p}=0.746)$ (Table 1$)$.

TABLE 1 - Functional variables analyzed in the groups.

\begin{tabular}{lccccc}
\hline VARIABLES & G1 & G2 & G3 & G4 & p \\
\hline MMP & 23.5 & 27.5 & 24.5 & 22.1 & 0.6303 \\
\hline BC & 0.48 & 0.28 & 0.37 & 0.15 & 0.1003 \\
\hline $\mathrm{F}$ & 1.5 & 1.1 & 1.8 & 0.9 & 0.5717 \\
\hline $\mathrm{TC}$ & 11.5 & 1.5 & 18.1 & 17.1 & $\mathbf{0 . 0 2 7 8 *}$ \\
\hline $\mathrm{TF}$ & 37.5 & 24.3 & 29.6 & 33.8 & 0.7460 \\
\hline $\mathrm{UPC}$ & 10.5 & 16.6 & 16.0 & 12.0 & $\mathbf{0 . 0 0 2 1 *}$ \\
\hline $\mathrm{UPF}$ & 8.3 & 10.7 & 13.5 & 8.6 & $\mathbf{0 . 0 7 6 9 *}$ \\
\hline
\end{tabular}

*Kruskal-Wallis non-parametric test

\section{Bladder contraction time (TC)}

There was a significant increase in this variable in the group of diabetic rats. The post hoc Dunn test revealed that this difference occurred between G1 and G3 animals ( $\mathrm{p}=0.0278$ )*.

\section{Urethral pressure during detrusor contraction (UPC)}

There was a significant difference between G1 and G2 $(\mathrm{p}=0.0121)^{*}$ and between $\mathrm{G} 1$ and G3 $(\mathrm{p}=0.001)$ (Figure 1).

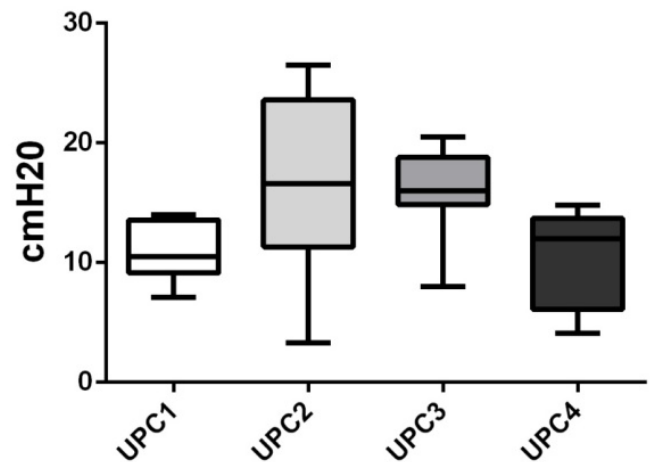

FIGURE 1 - Comparison of urethral pressure during detrusor contraction in $\mathrm{G} 1, \mathrm{G} 2, \mathrm{G} 3$ e $\mathrm{G} 4$ in $\mathrm{cmH}_{2} 0(\mathrm{G} 1 \mathrm{xG} 3 \mathrm{p}<0.001)$.

\section{Urethral pressure during bladder filling (UPF)}

There was no significant difference between groups in this variable. However, the $\mathrm{p}$ value was found to be quite close to the level of significance adopted $(p=0.07)$.

The variations in urethral pressure during the micturition cycle in normal (Figure 2a) and diabetic (Figure 2b) rats can be observed in the tracings of the urodynamic recordings. A deficit of urethral relaxation occurred in the diabetic animals, especially during the phase of bladder emptying, and an increase occurred in the time of detrusor contraction.
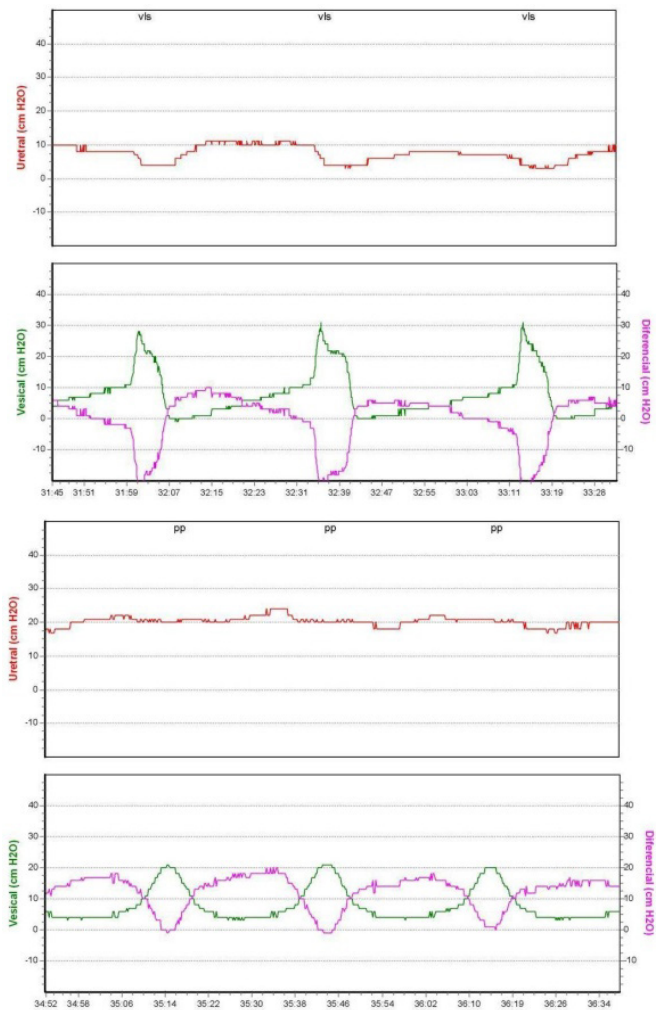

FIGURE 2 - a) Urodynamic evaluation of a healthy rat (G1) demonstrating voiding cycle normal. Can observe the relaxation of the urethra during the emptying phase. b) Urodynamic study of a diabetic rat (G3) showing elevated urethral pressure during voiding cycle. It is not possible to observe the relaxation of the urethra during voiding of the bladder. 
Time of detrusor contraction (Figure 3) and of urethral pressure during detrusor contraction (Figure 1) differed significantly between normal and diabetic rats. An important elevation of urethral pressure was observed during the phase of bladder filling, although the result was not statistically significant. After the administration of sildenafil citrate, a $35.3 \%$ reduction in urethral pressure occurred during the voiding phase (Figure 4) and a 36.2\% reduction occurred during the filling phase. The two results were found to be nonsignificant by statistical analysis $(\mathrm{p}<0.07)$, possibly due to the small sample size.

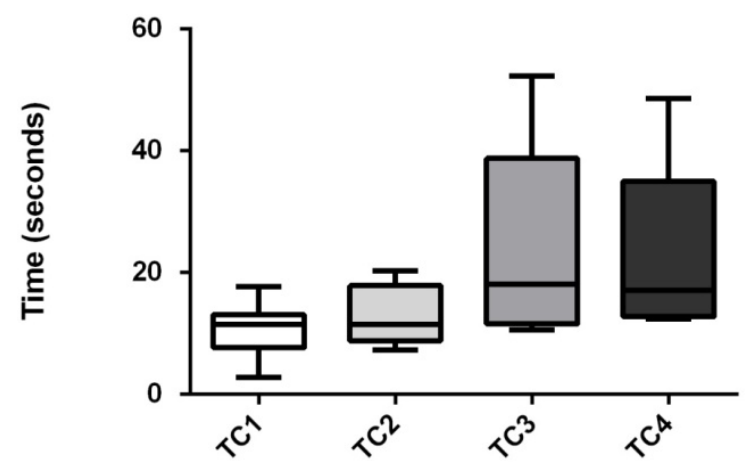

FIGURE 3 - Comparison of time detrusor contraction in G1, G2, G3 and $\mathrm{G} 4$ in seconds $(\mathrm{G} 1 \mathrm{xG} 3 \mathrm{p}<0.001)$.

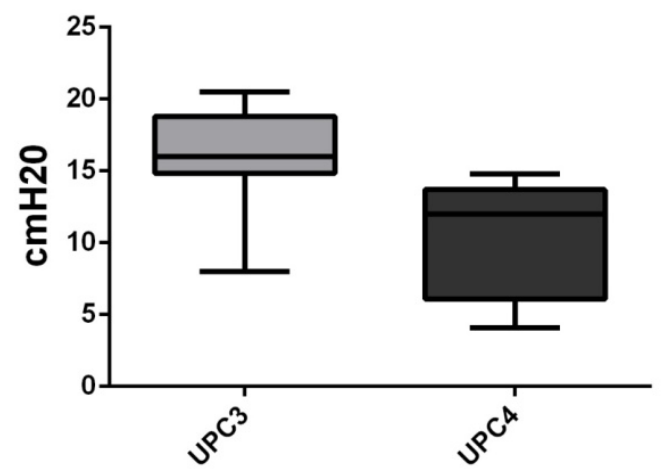

FIGURE 4 - Comparison of urethral pressure during contraction of the detrusor in groups $\mathrm{G} 3$ and $\mathrm{G} 4 \mathrm{in} \mathrm{cmH}_{2} 0$.

\section{Discussion}

DM has reached epidemic proportions around the world and its complications are determinants of the quality of life of the patient. Clinical manifestations of diabetic cystopathy frequently involve a variety of symptoms such as voiding difficulty, residual post-micturition volume, overflow urinary incontinence, and reduced micturition pressure ${ }^{4}$. However, it is common changes in the storage phase during early stages of the DM which include increased frequency, urgency and detrusor hyperactivity ${ }^{5}$.
The major finding of the present study was the significant increase in urethral pressure during detrusor contraction by six weeks after alloxan induction of diabetes. This elevation of urethral pressure increases the resistance to bladder voiding, suggesting that in diabetic rats the detrusor tries to compensate for the increased urethral pressure by increasing the time of bladder contraction so that complete voiding may occur.

This modification of urethral pressure is not considered to be significant during the phase of bladder filling in the early stages of diabetes. This demonstrates that the increase in urethral pressure is more pronounced during micturition, a fact that may promote incomplete micturition and the presence of a post-micturition residue characterized by the classical symptoms of DC.

In agreement with the present study, other authors have reported that female diabetic rats with a six week follow-up have a prolonged time of detrusor contraction compared to normal rats ${ }^{8}$. In the cited study, the objective of the authors was to assess the effects of diabetes on the activity of the outer sphincter of the urethra (OSU) with a follow-up time of six and twenty weeks. They demonstrated that there is a markedly increased of the OSU activity during micturition. However, OSU activity proved to be stable during the phase of bladder filling ${ }^{8}$.

The sympathetic nerves at the S2 to S4 medullary level supply the smooth muscle of the urethral sphincter and the somatic branches of the pelvic nerve innervate the striated muscle of the rhabdosphincter of the urethra ${ }^{9}$. The sympathetic innervation mediates the urethral contraction via $\alpha$-adrenergic receptors in the bladder neck and proximal urethra. The nitric oxide released by the postganglionic parasympathetic neurons mediates the urethral relaxation during the micturition reflex ${ }^{10}$. DC has been primarily attributed to peripheral polyneuropathy involving autonomic, somatic, sensory and motor nerves ${ }^{11}$. However, DM also impairs the urethral innervations and directly injures the urethral smooth and striated muscle. The result of diabetic urethropathy may degrade voiding function by the deficit caused in the innervation and in the reflexes between the urethra and the bladder

Yang et al. ${ }^{13}$ observed a significant deficit of urethral relaxation in rats by five to 10 weeks after induction of DM. They also observed that the increase in urethral resistance was due in part to the presence of vesical-sphincter dyssynergia (VSD), present in $30 \%$ of the diabetic rats studied and absent in all healthy rats. VSD was clearly demonstrated by the increased activity of tonic fibers of the external urethral sphincter and the cited study also revealed that treatment with alphabungarotoxin, a blocker of skeletal muscle activity, promoted a marked reduction of the urethral pressor profile in diabetic 
rats, suggesting that external urethral sphincter activity may be dysfunctional in the voiding cycle of DM.

Furthermore, the same study demonstrated that, in addition to urethral dysfunction of the external sphincter, there is also a reduction of relaxation of urethral smooth muscle mediated by nitric oxide (NO) and sensitization of urethral smooth muscle to alpha-adrenergic agonists. These last two effects are more pronounced over a more prolonged time of diabetes induction ${ }^{13}$.

$\mathrm{NO}$ is the major neurotransmitter that mediates the relaxation of urethral smooth muscle during micturition in rats and in other species ${ }^{14}$. Changes in NO production are involved in dysfunction of the penis, bladder and other organs. However, the involvement of changes in the production and efficacy of NO in urethral dysfunction due to diabetes has been little documented in the literature.

Relaxation effect of the phosphodiesterase-5 inhibition on the bladder and prostatic urethra and its therapeutic potentials for benign prostatic hyperplasia (BPH) and lower urinary tract symptoms (LUTS $)^{15}$ had been studied. Both clinical and preclinical studies have mostly shown beneficial effects for Phosphodiesterase-5 (PDE5 ) inhibitors in the treatment of lower urinary tract symptoms ${ }^{16}$. These recently studies demonstrated the impact of sildenafil on micturition behavior and urethral tone, and that irrespective of the hormonal status, sildenafil decreased leak point pressure by a nNOS-mediated mechanism ${ }^{15-17}$.

The findings of the present study suggest that in diabetic female rats the high levels of urethral pressure during micturition may be an important factor for the understanding of the physiopathology of DC.

Sildenafil citrate promoted partial relaxation of the urethra of about $35.3 \%$. Other study demonstrated significant relaxation of the bladder strips by $37.3 \%$ and of the urethra strips by $44.0 \%{ }^{15}$. This finding suggests that the phosphodiesterase- 5 inhibitors had relaxant effects on the urethra smooth muscle. The autor suggest that PDE-E inhibitors could be applied as an effective treatment ofr BPH and LUTS.

NO pathway contributes to the control of urethral function in diabetes, but is not the only pathway involved in this effect. There are other factors that control urethral function, such as the autonomic fibers, which provide the nerve supply for the urethra, and muscle fibers which, when altered, may promote $\mathrm{VSD}^{13}$. We may also cite the neutrotransmitters that mediate the relaxation of urethral smooth muscles such as carbon monoxide, vasoactive intestinal polypeptide, adenosine triphosphate, noradrenaline, and beta-adrenergic receptors.

Sildenafil citrate has been reported to act both on the bladder and on the bladder neck. In rats chronically treated (six weeks) with sildenafil citrate by the oral route, with treatment starting at the time of induction of mild obstruction of the bladder neck, there was prevention of hypertrophy of the detrusor muscle, detrusor hyperactivity and collagen deposition in the lamina propria and in smooth muscle, characteristic of bladder outlet obstruction ${ }^{18}$. In humans, daily Phospdiesterase 5 inhibitors (PDE5Is) alone or in association with alpha-blockers $\mathrm{AB}$ also demonstrate efficacy in this indication ${ }^{19}$.

In the present study, the treatment was acute, with the administration of a single dose of sildenafil citrate and urodynamic evaluation performed one hour later. Sildenafil citrate acted by partially reducing urethral pressure during micturition.

We did not observe changes in maximum detrusor contraction pressure after six weeks of alloxan-induced diabetes. Studies about this topic are controversial, with reports of increased $^{20,21}$, reduced ${ }^{22,23}$ or unchanged ${ }^{24}$ contractile responses.

The differences between reports may be due to different methodologies, differences in animal gender and variation in the time of diabetes induction. Although there is wide variability in the results of these studies, it can be seen that DM significantly changes the function of urethral smooth muscle, although little is effectively known about the possible mechanisms involved in these alterations.

\section{Conclusion}

Diabetes mellitus initially promotes urethral dysfunction characterized by increased urethral pressure during micturition. Sildenafil citrate acted by partially reducing the urethral pressure during micturition.

\section{References}

1. Franc C. Epidemiology of diabetes: frightening predictions. Med Sci (Paris). 2013;29(8-9):711-4.

2. Liu G, Daneshgari F. Alterations in neurogenically mediated contractile responses of urinary bladder in rats with diabetes. Am J Physiol Renal Physiol. 2005;288:1220-6.

3. Kaplan, SA, Te AE, Blaivas JG. Urodynamic findings in patients with diabetic cystopathy. J Urol. 1995;153:342-4.

4. Yoshimura N, Chancellor MB, Andersson KE, Christ GJ. Recent advances in understanding the biology of diabetes-associated bladder complications and novel therapy. BJU Int. 2005;95:733-8.

5. Uckert S, Oelke M. Phosphodiesterase (PDE) inhibitors in the treatment of lower urinary tract dysfunction. Br J Clin Pharmacol. 2011;72(2):197-204.

6. Mersdorf A, Schmidt RA, Tanagho EA. Urodynamic evaluation and electrical and pharmacologic neurostimulation. The rat model. Urol Res. 1993;21:199-209.

7. Suaid HJ, Rocha JN, Martins AC, Cologna AJ, Tucci SJ. Modulation of urethral alpha-sympathetic by parasympathetic before and following bethanechol chloride injection. In Braz J Urol. 2003;29:162-5. 
8. Daneshgari F, Liu G, Imrey PB. Time dependent changes in diabetic cystopathy in rats include compensated and decompensated bladder function. J Urol. 2006;176:380-6.

9. Strasser H, Bartsch G. Anatomy and innervation of the male urethra. Semin Urol Oncol. 2000;18:2-8.

10. Bennet BC, Kruse MN, Roppolo JR, Flood HD, Fraser MO, de Groat WC: Neural control of urethral outlet activity in vivo: role of nitric oxide. J Urol. 1995;153:2004-9.

11. Ueda T, Yoshimura N, Yoshida O. Diabetic cystopathy: relationship to autonomic neuropathy detected by sympathetic skin response. J Urol. 1997; 157:580-4.

12. De Groat WC, Fraser MO, Yoshimura M, Smerin S, Tai C, Chancellor MB. Neural control of the urethra. Scand J Urol Nephrol Suppl. 2001;(207):35-43.

13. Yang Z, Dolber PC, Fraser MO. Diabetic urethropathy compounds the effects of diabetic cystopathy. J Urol. 2007;178:2213-9.

14. Wibberley A, Nunn PA, Naylor AM, Ramage AG: An investigation of the effects of zaprinast, a PDE inhibitor, on the nitrergic control of the urethra in anaesthetized female rats. Br J Pharmacol. 2002;136:399-414.

15. Lee JG, Moon du G, Kang SH, Cho DY, Park HS, Bae JH. Relaxation effect of phosphodiesterase- 5 inhibitor on the animal bladder and prostatic urethra: in vitro and in vivo study. Urol Int. 2010;84(2):231-5.

16. Lin CS, Albersen $M$, Xin Z, Namiki M, Muller D, Lue TF, Phosphodiesterase-5 expression and function in the lower urinary tract: a critical review. Urology. 2013;81(3):480-7.

17. Gamé X, Bouali O, Allard J, Gourdy P, Escourrou G, Tack I, Rischmann P, Arnal JF, Malavaud B. Influence of sildenafil on micturition and urethral tone in ovariectomized and nonovariectomized mice. J Sex Med. 2012;9(2):466-71.

18. Beamon CR, Mazar C, Salkini MW, Phull HS, Comiter BC. The effect of sildenafil citrate on bladder outlet obstruction: a mouse model. BJU Int. 2009;104:252-6.

19. Game X, Cornu JN, Robert G, Descazeaud A, Droupy S, BernardLaribiere C, Guy L, Bruyere F, Karsenty G. Drugs for urethra. Prog Urol. 2013;23(15):1287-98.

20. Kolta MG, Wallace LJ, Gerald MC. Streptozotocin-induced diabetes affects rat urinary bladder response to autonomic agents. Diabetes. $1985 ; 34: 917-21$
21. Latifpour J, Grousse A, Yoshida M, Weiss RM. Muscarinic receptors in diabetic rat prostate. Biochem Pharmacol. 1991; 42 Suppl: S113-9.

22. Ichiyanagi N, Tsuji T, Masuda H, Kihara K, Goto M, Azuma H. Changed responsiveness of the detrusor in rabbits with alloxan induced hyperglycemia: possible role of 5-hydroxytryptamine for diabetic bladder dysfunction. J Urol. 2002;168:303-7.

23. Lincoln J, Crockett M, Haven AJ, Burnstock G. Rat bladder in the early stage of streptozotocin-induced diabetes: adrenergic and cholinergic innervations. Diabetologia. 1984;26:81-7.

24. Torimoto K, Fraser MO, Hirao Y, de Groat WC, Chancellor MB and Yoshimura N. Urethral dysfunction in diabetic rats. J Urol. 2004; 171:1959-64.

\section{Correspondence:}

Ana Beatriz Gomes de Souza Pegorare

Faculdade de Medicina de Ribeirão Preto

Departamento de Cirurgia e Anatomia

Divisão de Urologia

Avenida Bandeirantes, 3900

14048-900 Ribeirão Preto - SP Brasil

Tel./Fax: (55 16)3602-2453

beatrizgomes@usp.br

Received: Dez 12, 2013

Review: Feb 14, 2014

Accepted: March 11, 2014

Conflict of interest: none

Financial source: none

${ }^{1}$ Research performed at Laboratory of Surgical Technique and Experimental Surgery, Department of Surgery and Anatomy, Faculty of Medicine of Ribeirao Preto, University of Sao Paulo (FMRP-USP). Ribeirao Preto-SP, Brazil. Part of PhD degree thesis, Postgraduate Program in Surgery, Department of Surgery and Anatomy, FMRP-USP. Tutor: Haylton Jorge Suaid. 